\title{
A Pathway Model of Emotionally-Associated Predictors of US College Students' Career Indecision
}

\author{
Seungyeon Lee \& Magnus A. Gray \\ University of Arkansas at Monticello \\ Minsung Kim \\ Defense Language Institute Foreign Language Center
}

\begin{abstract}
This small-scale study establishes a pathway model to show a better understanding of how variables related to emotional intelligence (EI) affect career indecision in a college classroom. We investigated a total of 240 undergraduate students and a pathway model of direct and indirect effects surrounding career indecision was made by using structural equation modeling (SEM). Our pathway model shows a positive direct effect of procrastination on career indecision $(\beta=.13, \mathrm{p}<.001)$, with negative direct effects on EI, life satisfaction, CDSE, and planning, in terms of career conflict. EI shows a positive correlation with $\operatorname{CDSE}(\beta=.51, \mathrm{p}<.001)$. Findings indicate that emotionally-related variables are good predictors of psychology students' career concerns.
\end{abstract}

Keywords: Career decision self-efficacy (CDSE); career indecision; career student planning scale (CSPS); emotional intelligence (EI); procrastination

Psychology professors and university counselors have shown growing concerns about students' career advancement, given rapid changes due to the pandemic. Students with a major in psychology or a related field aim for a fulltime job after graduation, but the manner in which educators direct students is questionable. Those in the field of vocational psychology and career counseling offer a guide for students to fully reach their potential in the field (Blustein et al., 2019; Chung, 2002; MacCann et al., 2020; Spurk \& Straub, 2020). Psychological factors contributing to a student's career conflict continues to draw academic attention-especially if it is why they take psychology courses. Being a psychology major does not guarantee finding a 'dream' job; however, students taking these courses believe they will create a pathway of their own.

Students' major source of stress often results from work-related challenges (Blustein et al., 2019; Chung, 2002; Gray et al., 2020; Gray et al., 2021). Regardless of their field, psychology professors emphasize current psychological theories, research, practice, and classroom work that facilitate their students' intellectual abilities and also advance their career development. Yet, they map out a path to help students face realities and opportunities with psychological knowledge (Tatum \& Schwartz, 2020). Regression analysis from previous studies revealed that self-efficacy, career planning, and psychological distress on job security were the important predictors of career decision making (Gray et al., 2020; Gray et al., 2021; Gray et al., 2021).

This study is unique as it links a magnitude of variables in the same research design-something that has rarely been done on the topic of career development. Relatively few studies investigated the association between EI and career indecision; thus, our goal is to explore the associations among these variables and present a model of direct and indirect effects on career indecision. Gray et al. (2020) found a negative relationship between EI and indecision, but their sample size was small. The generalizability of their findings are somewhat limited $(N$ $=66$ in the 2020 study and $N=$ 136 in press). Sanchez-Ruiz and E1 Khoury (2019) established a pathway model to predict emotionally-related variables that affect 
CANADIAN

JOURNAL OF

CAREER

DEVELOPMENT
REVUE

CANADIENNE DE

DÉVELOPPEMENT

DE CARRIĖRE academic performance, except for GPA (not stipulated as part of the current performance, as it was already a built-in measure); it was used as a predictor of academic performance. Coetzee and Harry (2014) posited emotional functioning as similar to EI, which was a strong predictor of career adaptability, yet their findings were based on middle-aged adults in the job market. Little is known about the relationship between EI and career indecision in the psychology classroom; furthermore, other emotionally-laden constructs, such as procrastination, career planning, CDSE, and life satisfaction were found to contribute to career conflict, but not necessarily in one dimension: these constructs are variables that contribute to career issues.

To our knowledge, few studies explore the relationship between psychologically-related variables like EI and career indecision in a college classroom (Falco \& Summer, 2019; Gray et al., 2020; Gray et al., 2021; Gray et al., in press; Sanchez-Ruiz \& EI Khoury 2019; Tatum \& Schwartz, 2020). The novelty of the present study is twofold. We first investigated the contribution of EI, CDSE, CSPS, and life satisfaction to career planning in order to present a pathway model of direct and indirect effects of those variables on career indecision. This study is to provide a predictive model of college students' career indecision that shows a practical guideline in educational assessment of university classroom, using structural equation modeling (SEM).

\section{Methods}

\section{Participants and Procedures}

A total of 253 students was recruited from small, liberal arts colleges in southeast Arkansas and southern California. Thirteen participants did not respond to at least $20 \%$ of the survey items, which was excluded $(N=240$; 188 females, 52 males). Each student voluntarily participated in the study, approved the Institutional Review Board (IRB) at the primary investigator (PI)'s institution. Informed consent was obtained, so that 5-minute debriefing process that was used to assess any issues with the participants' well-being and provide the researchers' contact information could take place after completion. The distribution of self-identified race was $64.58 \%$ White, $28.33 \%$ Black/African-American, $0.42 \%$ Native American, and while the rest were indicated as 'other.' Twenty-six percent were freshmen, $25 \%$ were sophomores, $22 \%$ were juniors, $22 \%$ were seniors, and the rest indicated 'post-baccalaureate degrees.' All participants were full-time students at fouryear universities $(M=22.08, S D$ $=5.89$ ), recruited via email, with digital surveys administered after the pandemic lockdown. They were enrolled in either introductory psychology or upper-level developmental psychology course. Students received extra credit for participation.

\section{Measures}

Self-reported measures were used to assess participants' psychological characteristics. The main benefit of using those is that self-report data can be easily collected via online and the chosen measures are publicly available in general public. MacCann et al. (2020) and Gray et al. (2021) demonstrate that Wong and Law's emotional intelligence scale (WEIS), career student planning scale (CSPS), career decision self-efficacy short form (CDSE$\mathrm{SF}$ ), general procrastination scale (GPS), career decision difficulty questionnaire (CDDQ), and satisfaction with life scale (SWLS) are frequently used as a scale development with more response item categories in psychological studies. Those measures were chosen based on reported internal consistency reliability, which we also calculated for the present study.

\section{Career Decision Difficulty Questionnaire (CDDQ)}

The CDDQ measure was used to assess participant indecision as a dependent variable. Created in 1996 by Gati et al., it consists of the following subscales: (a) lack of readiness (CDDQ-R: lack of motivation, general indecisiveness, and dysfunctional beliefs); (b) lack of information (CDDQ-L: the stage of decision making while in an occupation, and the need for additional information); and (c) difficulties related to inconsistent information (CDDQ-D: unreliable information, 
as well as internal and external conflicts). This 34-item measure asks participants to rate the extent to which each statement illustrates their professional decisions on a 9-point Likert-type scale, ranging from 1 (does not describe me) to 9 (describes me well). Fabio, et al. (2015) found high internal consistency: (a) .89 for lack of readiness, (b) .90 for lack of information, and (c) .92 for inconsistent information. The Cronbach's alpha of this study was .94, which is consistent to Gati et al's study.

\section{Career Student Planning Scale (CSPS)}

An 8-item, unidimensional scale created by Gray et al. (2021) was used as a reliable measure of career planning. The CSPS uses a 5-point Likert-type scale ranging from 1 (strongly disagree) to 5 (strongly agree). All negatively-worded items were scored in reverse, showing the alpha coefficient of the scale to be .85 . The Cronbach's alpha of this study was .84 .

\section{Career Decision Self-efficacy Short-form (CDSE-SF)}

Taylor and Betz's (1983)

CDSE-SF measure was used in this study to assess each participant's career-related SE. The 25-item form includes career SE and self-reported frequency on a 5-point Likert-type scale, ranging from 1 (no confidence) to 5 (complete confidence). Our calculated Cronbach's alpha was .94.

\section{Wong and Law's Emotional Intelligence Scale (WLEIS)}

Wong and Law's EI scale (2002) assessed participant suitability for specific workplace situations. It contains four subscales that assess core branches of emotion-related aibilities: (a) perceiving self-emotion, (b) perceiving other's emotions, (c) expressing emotions, and (d) managing emotions. The authors designed the scale specifically after Brackett et al. (2006) developed the four-branch model in their EI scale. Participants were scored on 16 items (every four items were deemed to be one factor, so a 4-factor structure emerged) on a 7-Likert-type scale from 1 (strongly disagree) to 7 (strongly agree). Our Cronbach's alpha for WLEIS included these four factors and was .90 .

\section{General Procrastination Scale (GPS)}

The GPS (Lay, 1986) was used to assess participants' tendency to procrastinate; they were scored on 20 items with a 5-point Likert-type scale ranging from 1 (extremely uncharacteristic) to 5 (extremely characteristic). Our study's calculated Cronbach's alpha was 0.78 .

\section{Satisfaction with Life Scale (SWLS)}

\section{Diener et al's SWLS} (1985) rated participants' satisfaction with their lives. This 5-item self-reported instrument used a 7-point Likert-type scale ranging from 1 (strongly disagree) to 7 (strongly agree). Our Cronbach's alpha for SWLS was .88.

\section{Results}

\section{Data Analysis Plan}

Data were analyzed with Excel software and R. We conducted a simple regression analysis, as Table 1 shows correlations among study variables. CDDQ negatively correlated with EI ( $r=$ $-.27, p<.001)$, CDSE $(r=-.43, p$ $<.001)$, CSPS $(r=-.27, p<.001)$, and SWLS $(r=-.33, p<.001)$, but positively correlated with GPS $(r=.21, p<.001)$. EI negatively correlated with GPS $(r=-.30, p$ $<.001)$, and positively correlated with CDSE $(r=.55, p<.001)$, CSPS $(r=.35, p<.001)$, and SWLS $(r=.51, p<.001)$. A negative correlation was found between GPS and SWLS $(r=-.26, p<.01)$.

\section{Mediation Model}

The mediation model for CDSE, CSPS, and CDDQ show a positive effect of CSPS, mediated by CDSE and CDDQ (Figure 1). The effect of CDSE on CDDQ was mediated by CSPS. The regression coefficient for CDSE and CDDQ, and CSPS and CDDQ, were significant. The indirect effect was $(.19) *(-.09)=-0.02$, so we tested significance with bootstrapping procedures. Unstandardized indirect effects were computed for 1,000 bootstrapped samples, with a $90 \%$ CI for indirect effects at the $2.5^{\text {th }}$ and $97.5^{\text {th }}$ percentiles (Hair, Black, Babin, \& Anderson, 
Table 1

Correlations among study variables

\begin{tabular}{|c|c|c|c|c|c|}
\hline & CSPS & EI & CDSE & CDDQ & GPS \\
\hline EI & $0.35 * * *$ & & & & \\
\hline CDSE & $0.51 * * *$ & $0.55 * * *$ & & & \\
\hline CDDQ & $-0.51 * * *$ & $-0.27 * * *$ & $-0.43 * * *$ & & \\
\hline GPS & $-0.20 * *$ & $-0.30 * * *$ & $-0.27 * * *$ & $0.21 * * *$ & \\
\hline SWLS & 0.08 & $0.51 * * *$ & $0.32 * * *$ & $-0.33 * * *$ & $-0.26 * *$ \\
\hline
\end{tabular}

Figure 1

Mediation model among the given variables

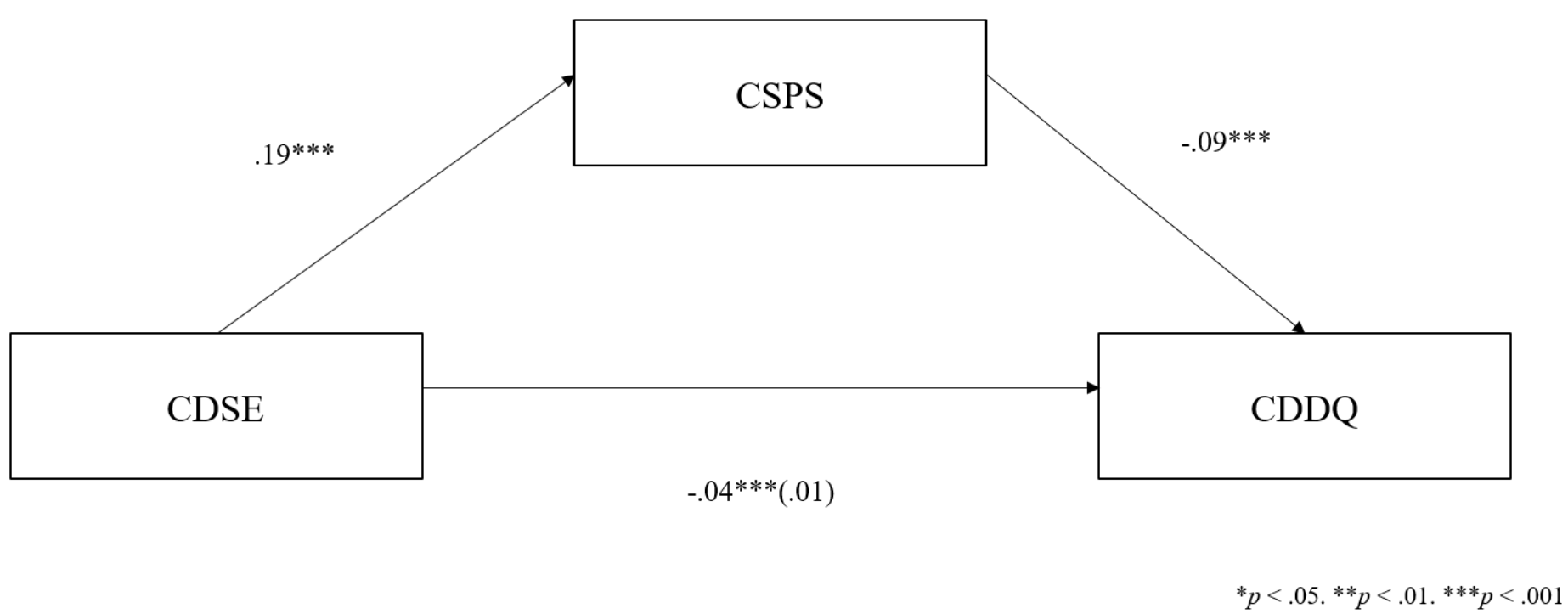

2019). The bootstrapped unstandardized effect was -.02 , as the $95 \%$ CI ranged from - .03 to .01 . The indirect effect was statistically significant at $p<.01$.

\section{Path Analysis}

\section{Model Fit}

The model included indirect effects between EI and CDDQ, and GPS, and SWLS (Figure 2). CDSE was hypothesized to have indirect effects on CDDQ, with GPS, SWLS, and CSPS as mediating factors. SWLS and CSPS were expected to have a negative effect on CDDQ, while Figure 2 illustrated the model with its respective path coefficients. The comparative fit index (CFI) with values above .90 indicates a good fit. The standardized root mean square residual (SRMR) with values below .08 also indicates a good fit. Based on these indices, the hypothesized model revealed a 
Figure 2

A pathway model with significance

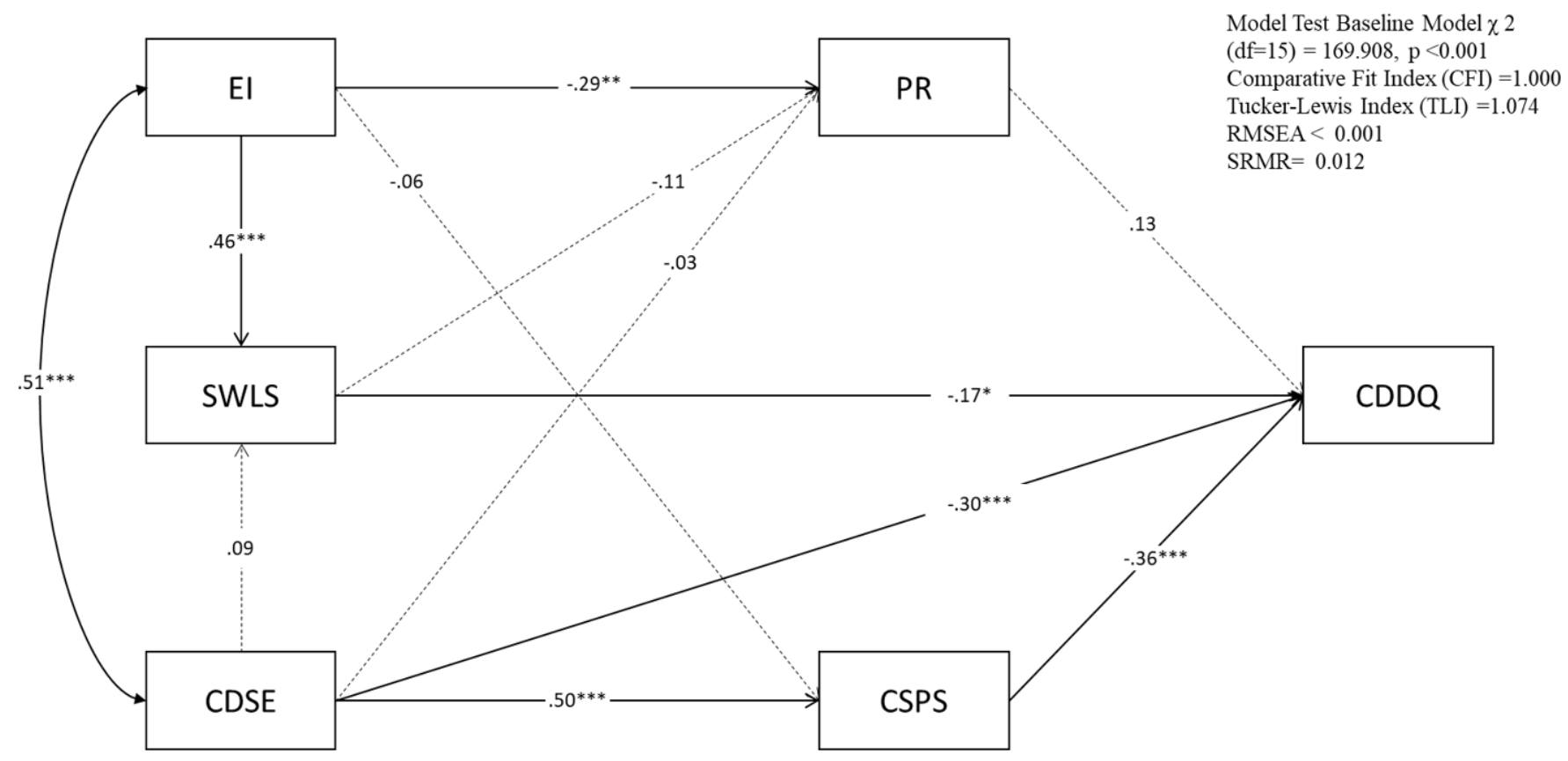

good fit with the root mean square error of approximation (RMSEA), with values between 0 and .05 , Model $\chi^{2}=169.908, \Delta \mathrm{df}=15, p$ $<.001, \mathrm{CFI}=1.000, \mathrm{RMSEA}<$ $.001, \mathrm{SRMR}=0.012$.

\section{Direct and Indirect Effects}

CSPS had a significant direct effect on CDDQ with $\beta=-.36$, $p<.001$. SWLS also had a marginally significant effect on CDDQ with $\beta=-.17, p<.05$, whereas no significant effect was found between GPS and CDDQ. CDSE had a significant direct effect on CDDQ $(\beta=-.30, p<.001)$ and $\operatorname{CSPS}(\beta=.50, p<.001)$. EI and CDSE showed a positive correlation $(\mathrm{r}=.51, p<.001)$.

\section{Discussion}

This study explored how EI, CSPS, CDSE-SF, and GPS are related to career indecision; though findings suggest that EI is negatively correlated to it, substantiating the work of Gray et al. (2020; in press). Procrastination is positively related to career conflict, whereas both career planning and career related self-efficacy show a negative correlation. Our results are generally in agreement with previous studies (Gray et al., 2020; Gray et al., 2021; Gottlieb \& Gøtzsche-Astrup, 2020; MacCann et al., 2020; Sanchez-Ruiz \& El Khoury; Wilmot et al., 2019).

These findings shed light on emotionally-related variables, such as EI, for students' motivation toward career development during higher education. Psychol- ogy instructors with an interest in the field of counseling psychology or those who teach a capstone course may want to assess conscientious behaviors, such as EI and CDSE, which impact students' academic engagement and life satisfaction, and ways to advance one's career. Future studies could explore the relationship between EI and career indecision (and other associated variables) at the factor level because EI, in particular, is related to a variety of psychological constructs depending on whether researchers focus on college students' self-control, emotionality, and/or social relationship (Mavroveli \& Sanchez-Ruiz, 2011). CDSE and life satisfaction directly predicted career indecision, while EI and CDSE are positively correlated with each other . The study has several limitations: 
the chosen sampling method was convenience sampling, so the generalizability of the findings is somewhat constrained. More diverse samples with mixed methods or longitudinal designs would be highly desired for future research. All variables are assessed with self-reported measures, so that the mono-method bias would a possibility. Future research could benefit from incorporating more variables (e.g., self-control or in-class test scores), along with possible moderators to assess the association among variables. Despite its limitations, this study offers a preliminary investigation that develops a practical theoretical framework, with a predictive model of college students' career indecision. Replications of this study with larger sample sizes may yield better results, and could be an integral part of educational assessment and career counseling. The relevance of this area is continuously expanding, so that educators must be aware of it. Future research with this pathway model can be extended to grapple with a wide array of psychological processes, while simultaneously working with young adults who will soon be in the workforce. Career advancement requires more than just 'being smart' and hardworking. We need better understanding of psychological characteristics that need for student success.

\section{References}

Blustein, D. L., Ali, S. R., \& Flores, Lisa Y. (2019). Voca- tional psychology : Expanding the vision and enhancing the impact. The Counseling Psychologist, 47(2), 166-221. https://doi.org/10.1177\%2F00 11000019861213

Brackett, M. A., Rivers, S. E., Shiffman, S., Learner, N., \& Salovey, P. (2006). Relating emotional abilities to social functioning: A comparison of self-report and performance measures of emotional intelligence. Journal of Personality and Social Psychology, 91, 780-795. https://doi.org/10.1037/00223514.91.4.780

Chung, Y. B. (2002). Career decision-making self-efficacy and career commitment: Gender and ethnic differences among college students. Journal of Career Development, 28, 277284. https://psycnet.apa.org/ oi/10.1023/A:1015146122546

Coetzee, M., \& Harry, N. (2014). Emotional intelligence as a predictor of employees' career adaptability. Journal of Vocational Behavior, 84, 9097. https://doi.org/10.1016/j. jvb.2013.09.001

Falco, L. D., \& Summer, J. J. (2019). Comparing ability and self-report trait emotional emotional intelligence, fluid intelligence, and personality traits in career decision. Personality and Individual Differences, 64, 174-178. https://doi.org/10.1016/j. paid.2014.02.024

Gati, I., Krausz, M., \& Osipow, S. H. (1996). A taxonomy of difficulties in career decision making. Journal of Counseling Psychology, 43(4), 510-526. https://doi.apa.org/ doiLanding?doi $=10.1037 \%$ 2F0022-0167.43.4.510 Gray, M. A., Kim, M., \& Lee, S. (2021). Simplifying the measurement of college students' career planning: the development of career student planning scale during the COVID-19 pandemic. Experimental Results, 2, e4, 1-9. https://doi.org/10.1017/ exp.2020.69

Gray, M. A., Kim, M., \& Lee, S. (2021). Career self-efficacy as a mediator between emotional intelligence and employment planning among US college students. Canadian Journal of Career Development, 20(2), 70-76.

Gray, M. A., Lee, S., \& Kim, M. (2020). Comparing self-reported emotional intelligence, self-efficacy, and personality traits in college students' career decision-making: A pilot study. In S. Lee (Ed.), Exploring the opportunities and challenges of college students (pp. 205-217). NOVA Science Publishers, Inc.

Hair, Jr., J.F., Black, W.C., Babin, B.J., \& Anderson, R.E. (2019). Multivariate analysis (8th ed.). Cengage.

Işik, E. (2012). The relationship of career decision self-efficacy, trait anxiety, and affectivity among undergraduate students. Psychological Reports: Human Resources \& Marketing, 111(3), 805-813. https:// doi.org/10.2466/01.09.10. 
PR0.111.6.805-813

Jiang, Z. (2016). Emotional intelligence and career decision-making self-efficacy: Mediating roles of goal commitment and professional commitment. Journal of Employment Counseling, 53(1), 30-47. https://doi. org/10.1002/joec. 12026

Law, K. S., Wang, C. S., \& Song, L. J. (2004). The construct and criterion validity of emotional intelligence and its potential utilities for management studies. Journal of Applied Psychology, 89(3), 483-496. https:// doi.org/10.1037/0021$\underline{9010.89 .3 .483}$

MacCann, C., Jiang, Y., Brown, L. E. R., Double, K. S., Bucich, M., \& Minbashian A. (2020). Emotional intelligence predicts academic performance: A meta-analysis. Psychological Bulletin, 146(2), 150186. http://doi.org/10.1037/ bu10000219

Mavronvelli, S., \& Sanchez-Ruiz, M. J. (2011). Trait emotional intelligence influences on academic achievement and school behavior. British Journal of Educational Psychology, 81(Pt1), 112-134. https://doi.org/10.1348/2044$\underline{8279.002009}$

Mojgan, F. N., Kadir, R. A., \& Soheil, S. (2011). The relationship between state and trait anxiety with career indecision of undergraduate students. International Education Studies, 4(3), 31-35. https://doi. org/10.5539/ies.v4n3p31
Sanchez-Ruiz, M-J., \& El

Khoury, J. (2019). A model of academic, personality, and emotion- related predictors of university academic performance. Frontiers in Psychology, 10, e2345. https://doi.org/10.3389/ fpsyg. 2019.02435

Spurk, D., \& Straub, C. (2020). Flexible employment relationships and careers in times of the COVID-19 pandemic. Journal of Vocational Behavior, 119, e103435. https://doi.org/10.1016/j. jvb.2020.103435

Tatum, H. E., \& Schwartz, B. M. (2020). Chapter 7 Best practice - the capstone course in psychology: Addressing challenges and incorporating best practices. In A. Schwarz andR. L. Miller (eds), High impact educational practices: A review of best practices with illustrated examples (pp. 126-139). Society for the Teaching of Psychology. Taylor, K. M., \& Betz, N. E. (1983). Applications of self-efficacy theory to the understanding and treatment of career indecision. Journal of Vocational Behavior, 22(1), 63-81. https:// doi.org/10.1016/00018791(83)90006-4

Wong, C. S., \& Law, K. S. (2002). Wong and Law emotional intelligence scale (WLEIS). [Database record]. APA Psyc Tests.https://psycnet.apa.org/ doi/10.1037/t07398-000 